patient concerned, i.e. the 'ends' he or she is pursuing. However, 'the goals of the patient concerned' can be problematic in the cognitive enhancement debate and this formulation can conceal important ethical issues.

Spence mentioned the concept of meta-responsibility, the fact that somebody can be responsible for becoming irresponsible, in the case of the example that somebody can be responsible for deciding not to take medication. ${ }^{2}$ In a somewhat similar way as Mitchell, Frankfurt ${ }^{3}$ discussed the difference between first- and second-order desires. One can have a desire for smoking, which is a first-order desire. One can also have a second-order desire, namely the desire not to have the desire for smoking.

One could argue that in the future pharmacological interventions might be able to interfere with second-order desires. Second-order desires according to Frankfurt are the core aspect of personhood. Even if one does not want to go as far as Frankfurt in stating that the second-order desires determine personhood, moral enhancement treatment can be problematic if it could change second-order desires. In that case, people's goals would alter. Contrary to Spence's view, moral enhancement pharmacotherapy can be quite controversial if it interferes with secondorder desires.

1 Spence SA. Can pharmacology help enhance human morality? Br J Psychiatry 2008; 193: 179-80.

2 Mitchell EW. Madness and meta-responsibility: the culpable causation of mental disorder and the insanity defence. J Forensic Psychiatr 1999; 10: 597-622.

3 Frankfurt H. Freedom of the will and the concept of a person. J Philos 1971; 58: 5-20.

Dieneke Hubbeling, South West London and St George's Mental Health NHS Trust, London, UK. Email: dieneke@doctors.org.uk

doi: 10.1192/bjp.194.2.187b

Author's reply: The varied correspondence precipitated by my editorial has invoked a great many issues. However, the sole aim of my original piece was to examine whether a current concern with the putative cognitive-enhancing effects of certain medications might be redirected towards the possible enhancement of other human attributes such as moral behaviour. ${ }^{1}$ Should this be of interest to psychiatrists? Well, I believe that there is something worth scrutinising within the medical consultation when a patient (a moral agent) considers the likely impact of their future conduct upon others, and the various means via which such conduct might be modulated. Drugs are not the only means by which such modulation might occur but they do provide an interesting example. Nevertheless, as I acknowledged in the editorial, such a juxtaposition of pharmacology with morality risks provoking reflexive responses: strong opinions unencumbered by reflection.

Clearly, the situation in the consulting room with an antisocial or aggressive man is rather different from that outlined by Al-Adwani. We are not talking about the social consumption of stimulants and intoxicants or the enforced ingestion of medicines by combatants in order for them to fight for longer. We are talking about what individual patients might choose to do about their own future behaviours, sometimes under very difficult circumstances; indeed, an antisocial male may not even enjoy a community of peers with whom to consume coca, kratom or qat. I apologise if this was not sufficiently obvious.

With respect to Frankfurt's conjecture that we might all harbour first- and second-order desires, Hubbeling's point is well taken: that if we posit such a hierarchy of desiring processes, then an individual's second-order (pro-social) desire to control an aberrant first-order desire (to react aggressively, to assault someone) might utilise a pharmaceutical agent only, to discover (later on) that the latter had modulated not only the first-order construct but the second-order one as well. The questions arising, here, are: (a) whether such first-order and second-order desires enjoy any empirical demonstration of their existence; and (b) whether, if second-order desires really exist, we are currently managing to avoid affecting them when we prescribe psychotropic medications or engage in any form of dynamic psychotherapy. To my mind, this makes the central question of even greater interest and one deserving of further empirical exploration.

1 Spence SA. Can pharmacology help enhance human morality? Br J Psychiatry 2008: 193: 179-80.

Sean A. Spence, Academic Clinical Psychiatry, University of Sheffield The Longley Centre, Norwood Grange Drive, Sheffield S5 7JT, UK. Email: S.A.Spence@Sheffield.ac.uk

doi: 10.1192/bjp.194.2.188

\section{Duration of untreated psychosis in LAMI countries}

I have some reservations regarding the conclusions drawn by Large et $a l^{1}$ in their study on duration of untreated psychosis in low- and middle-income (LAMI) countries. This is because the samples are not really representative of the occurrence of psychosis. It seems, people with untreated psychosis who have recovered or remitted without antipsychotic or medical treatment are excluded from this study. There is enough evidence that in LAMI countries, a substantial proportion of patients with psychosis seek treatment from traditional healers, ${ }^{2}$ use indigenous methods based on their non-biomedical beliefs ${ }^{3}$ or pathways to care. $^{4,5}$ Perhaps, many of those who fail to respond to these methods seek psychiatric help. Thus, the sample which reaches psychiatric services is a biased one. In clinical practice, we do encounter patients who have had previous episodes of psychosis which remitted spontaneously or by indigenous methods. Studies on duration of untreated psychosis should be community or general population based to overcome the confounding effects of non-psychiatric treatments and biased sampling. This is true more so for LAMI countries where such non-medical services are popular, in contrast to high-income countries ${ }^{6}$ with wellorganised health services, where any patient with psychosis is likely to reach psychiatric services without the pathway to care through non-psychiatric methods. This limitation needs a mention by the authors. ${ }^{1}$

1 Large M, Farooq S, Nielssen O, Slade T. Relationship between gross domestic product and duration of untreated psychosis in low- and middle-income countries. Br J Psychiatry 2008; 193: 272-8.

2 Razali SM, Mohd Yasin MA. Complementary treatment of psychotic and epileptic patients in Malaysia. Transcult Psychiatry 2008; 45: 455-69.

3 Sarvanan B, Jakob KS, Deepak MG, Prince M, David AS, Bhugra D. Perceptions about psychosis and psychiatric services: a qualitative study from Vellore, India. Soc Psychiatry Psychiatr Epidemol 2008; 43: 231-8.

4 Kulhara P. Transcultural variations in schizophrenia: some research issues. Indian J Psychiatry 2001; 43: 1-4.

5 Chong SA, Mythili, Lum A, Chan YH, McGorry P. Determinants of duration of untreated psychosis and the pathway to care in Singapore. Int J Soc Psychiatry 2005; 51: 55-62.

6 Temmingh HS, Oosthuizen PP. Pathways to care and treatment delays in first and multi episode psychosis. Findings from a developing country. SoC Psychiatry Psychiatr Epidemiol 2008; 43: 727-5.

Santosh K. Chaturvedi, Department of Psychiatry, National Institute of Mental Health and Neurosciences, Hosur Road, Bangalore - 560029, India. Email: skchatur@gmail.com

doi: 10.1192/bjp.194.2.188a 